\title{
ANALISIS KUALITAS SUMBER DAYA MANUSIA, SISTEM PENGENDALIAN INTERNAL, KOMUNIKASI INTERPERSONAL TERHADAP KINERJA PEGAWAI NEGERI SIPIL
}

\author{
Endang Brotojoyo ${ }^{1}$ \\ Veronica Titi Purwantini ${ }^{2}$ \\ ${ }^{1,2}$ Program Studi Manajemen, STIE Adi Unggul Bhirawa Surakarta \\ Email: brotojoyo.endang@stie-aub.ac.id; veronica_purwantini@yahoo.co.id
}

\begin{abstract}
This study analyzes the quality of human resources, internal control systems, and interpersonal communication on civil servants' performance in the Karanganyar Regency. In running the government, the quality of reliable human resources has a major role in organizational activities. This research method uses a type of causality research with data analysis stages consisting of instrument testing, classical assumption test, multiple linear regression analysis, individual parameter test, simultaneous test, and determination coefficient tests $\left(R^{2}\right)$. The results of multiple analyses show that the quality of human resources, internal control systems, and interpersonal communication positively affect employee performance. The F test results show that together the variables of human resource quality, internal control systems, and interpersonal communication have a significant effect on employee performance. The $R^{2}$ test result is 0.302, which means that the performance of employees in Karanganyar Regency can be explained by the variables of human resources, the internal control system, and interpersonal communication by 30.2 percent. In comparison, the remaining 69.8 percent was explained by other variables that were not observed, such as national culture, leadership, and commitment. Key Words: Human Resources, Internal Control System, and Interpersonal Communication
\end{abstract}

\begin{abstract}
ABSTRAK
Penelitian ini menganalisis kualitas sumber daya manusia, sistem pengendalian internal, dan komunikasi interpersonal terhadap kinerja PNS di Kabupaten Karanganyar. Dalam menjalankan pemerintahan, kualitas sumber daya manusia yang handal memiliki peran utama dalam kegiatan organisasi. Metode penelitian ini menggunakan jenis penelitian kausalitas dengan tahapan analisis data yang terdiri dari pengujian instrumen, uji asumsi klasik, analisis regresi linier
\end{abstract}


berganda, uji parameter individu, uji simultan, dan uji koefisien determinasi $\left(\mathrm{R}^{2}\right)$. Hasil analisis ganda menunjukkan bahwa kualitas sumber daya manusia, sistem pengendalian internal, dan komunikasi interpersonal berpengaruh positif terhadap kinerja karyawan. Hasil uji $\mathrm{F}$ menunjukkan bahwa secara bersama-sama variabel kualitas sumber daya manusia, sistem pengendalian internal, dan komunikasi interpersonal berpengaruh signifikan terhadap kinerja pegawai. Hasil uji $\mathrm{R}^{2}$ sebesar 0,302 yang artinya kinerja pegawai di Kabupaten Karanganyar dapat dijelaskan oleh variabel sumber daya manusia, sistem pengendalian intern, dan komunikasi interpersonal sebesar 30,2 persen. Sebagai perbandingan, 69,8 persen sisanya dijelaskan oleh variabel lain yang tidak diamati, seperti budaya nasional, kepemimpinan, dan komitmen.

Kata kunci: Sumber Daya Manusia, Sistem Pengendalian Internal, dan Komunikasi Interpersonal

\section{PENDAHULUAN}

Pelaksanaan dalam era reformasi memiliki tantangan yang semakin besar bagi lembaga pemerintah terutama kinerjanya dalam melakukan pelayanan terhadap masyarakat (Sutjiatmi, 2010). Nilai tambah dari sebuah organisasi sangat penting bagi konsumen untuk mendapatkan hak atas pelayanan tersebut, terlebih lagi untuk memotivasi konsumen dalam rangka mendukung kualitas atau mutu organisasi tersebut (Husain \& Sani, 2020). Dalam organisasi Pemerintah, khususnya Pemerintah Daerah menjadi semakin kuat dengan diberlakukannya Otonomi Daerah. Otonomi daerah menyiratkan seperangkat tantangan yang tidak kecil bagi Pemerintah Daerah dalam rangka mempercepat pelaksanaan roda pemerintah, pembangunan, dan pelayanan publik dalam wilayahnya masing-masing. Sejalan dengan Undang-undang Nomor 32 tahun 2004 tentang Pemerintah Daerah telah membawa perubahan mendasar dalam kehidupan birokasi di Indonesia. Pemberian kewenangan otonomi yang luas kepada pemerintah daerah melalui UU tersebut, dapat mewujudkan kesejahteraan masyarakat dalam peningkatan pelayanan, pemberdayaan dan juga peran masyarakat, serta daya saing daerah (Hamid, 2011).

Beberapa fenomena yang terjadi dan banyaknya ogranisasi dalam menilai kualitas kinerja karyawannya sendiri menghadapi subjektifitas dari masing-masing pimpinannya yang terkadang cenderung mengabaikan capaian kinerjanya (Wiranata, Irwansyah, Budiyantara, \& Sani, 2020). Pentingnya kemampuan dan potensi yang tinggi untuk mendukung pencapaian 
tujuan instansi yakni dengan kinerja yang baik bagi pegawai khususnya PNS agar dapat membantu melaksanakan tugas dan fungsi secara baik. Kinerja yang baik akan berdampak pada upaya pencapaian tujuan instansi pegawai negeri sipil kota Manado (Londong, Saerang, \& Koleangan, 2015). Menurut Moeheriono (2014:11), kinerja juga mencakup unsur tugas, wewenang dan tanggungjawab untuk mencapai tujuan organisasi dengan tidak melakukan pelanggaran hukun (bertindak secara legal) serta menjunjung tinggi etika, yang dilakukan studi pada karyawan perusahaan di wilayah kabupaten Karawang (Sungkono \& Tuhagana, 2020). Kinerja dalam aparatur Pemerintah Daerah SKPD se-Kabupaten Banyumas dalam pengembangan kualitas sumber daya manusia dapat membantu dalam proses pengendalian dan pengawasan, monitoring serta evaluasi pekerjaan hingga pencatatan informasi keuangan secara lebih spesifik melalui pelatihan dan pendidikan kepada aparatur Pemerintah Daerah yang bersangkutan (Aziz, Pratiwi, \& Suyono, 2018).

Kinerja pegawai sangat penting karena merupakan landasan dalam penyelenggaraan pemerintah. "Kinerja pegawai adalah hasil kerja yang dicapai oleh seorang pegawai dalam melaksanakan tugas yang diberikan kepadanya sesuai dengan wewenang dan tanggung jawab masing-masing dalam upaya pencapaian tujuan organisasi yang tidak bertentangan dengan moral dan etika" (Rivai, 2015). Kualitas sumber daya manusia adalah unsur yang penting untuk mencapai keberhasilan suatu organisasi termasuk pemerintah daerah. Menurut Hasibuan (2017), Sumber Daya Manusia terdiri dari daya fikir dan daya fisik manusia. Dalam penyelenggaraan Pemerintah, kualitas sumber daya manusia yang handal memiliki peranan utama dalam kegiatan organisasi.

Aspek pengendalian internal juga memiliki peranan yang sangat penting untuk mengidenfitikasi, menganalisis dan menilai risiko yang melekat pada organisasi sebagaimana diatur oleh Pernyataan Standar Audit (Statement on Auditing Standards - SAS) No. 78 (Husain, 2017). Pengendalian internal merupakan proses yang dilakukan oleh organisasi atas aktivitas yang mencakup aspek reviu, audit, pemantauan dan pengawasan lainnya secara menyeluruh dalam rangka pelaksanaan fungsi dan tugas, hal ini akan dijadikan sebagai tolok ukur atau output dan wujud tata kelola Kepemerintahan yang baik secara efisien dan efektif (Zahro, 2016). Lebih lanjut, Sistem Pengendalian Internal Pemerintah (SPIP) pusat maupun daerah yang diatur dalam Peraturan Pemerintah Nomor 60 tahun 2008. Perencanaan organisasi, metode, dan ukuran yang digunakan dalam suatu organisasi untuk mempertahankan aset, menguji akurasi dan reliabilitas data akuntansi, efisiensi operasional dan mendorong kepatuhan terhadap ketentuan kebijakan-kebijakan manajerial juga merupakan definisi dari pengendalian 
(Aziz, Pratiwi, \& Suyono, 2018). Pengendalian juga mencakup level pengawasan yang dibebankan oleh organisasi dan ditujukan kepada karyawan yang dirasakan dimana kualitas menjadi bentuk pengawasan, bimbingan serta arahan yang diterima dari atasan kepada bawahan (Rismayadi \& Maemunah, 2018)

Masalah komunikasi interpersonal juga merupakan salah satu faktor yang sangat krusial. Komunikasi berperan dalam kehidupan sehari-hari yang dimiliki setiap individu atau pegawai untuk berkomunikasi dengan pimpinan, rekan kerja maupun masyarakat. Komunikasi interpersonal atau komunikasi antar pribadi ialah komunikasi antara orang-orang secara langsung atau bertatap muka, yang memungkinkan setiap pesertanya menangkap reaksi dari pesan yang disampaikan secara langsung, baik secara verbal maupun non verbal (Roem, 2019). Komunikasi internal yang baik dan kordinasi antar rekan kerja menjadikan karyawan merasa lebih dihargai melalui pendapat yang didengarkan serta lebih merasakan keterlibatannya di dalam perusahaan (Pangendaheng, 2018).

Pengetahuan berkembang dari rasa ingin tahu yang merupakan ciri khas manusia karena manusia adalah satu-satunya makhluk yang mengembangkan ilmu dengan sungguh-sungguh (Hady, Henderi, \& Putri, 2018), hal ini dapat dilakukan melalui riset atau penelitian lebih lanjut. Berdasarkan rilis data dari Biro Pusat Statistik pada tahun 2019 diketahui bahwa aparat pegawai di wilayah Karanganyar sebanyak 8.949 yang didominasi oleh Golongan III dan IV sebanyak lebih dari 6.000 sehingga diperlukan pengelolaan manajemen sumber daya manusia, khususnya dalam aspek SPIP dan komunikasi interpersonal yang mendukung dalam aktivitas sehari-hari. Oleh karenanya, pentingnya penelitian ini akan dikaji secara mendalam mengenai faktor yang mempengaruhi kinerja pegawai PNS Kabupaten Karanganyar.

Faktor yang mempengaruhi kinerja pegawai PNS Kabupaten Karanganyar antara lain adanya kualitas sumber daya manusia untuk melaksanakan tujuan secara baik atau sesuai dengan aturan/wewenang, sistem pengendalian internal yang dilakukan sesuai dengan tujuan dan program sehingga efisiensi dan kebijakan manajemen dapat terpenuhi, dan juga komunikasi interpersonal yang dilakukan antar pegawai. Ketiga faktor tersebut sangat berdampak pada kinerja pegawai sehingga penting dikaji lebih lanjut untuk meningkatkan kinerja karyawan di lingkungan pegawai aparatur Pemerintah Kabupaten Karanganyar.

\section{METODE PENELITIAN}

Jenis Penelitian 
Jenis penelitian ini merupakan kategori eksplanasi ilmu dengan causal research (Supranto \& Limakrisna, 2019, p. 3) yang bertujuan mencari penjelasan dalam bentuk hubungan sebab-akibat. Pendekatan penelitian ini menggunakan metode kuantiatif.

\section{Waktu dan Tempat Penelitian}

Lokasi penelitian dilakukan di Kantor Kabupaten Karanganyar selama tahun 2020, dan subjek penelitian adalah Pegawai Negeri Sipil (PNS) di Kabupaten Karanganyar.

\section{Prosedur Penelitian}

Prosedur penelitian dalam riset kausalitas memerlukan jenis rancangan (experimental design) yang digunakan dalam suatu framework. Model proses dalam menghasilkan informasi penting digunakan sebagai kerangka kerja dan outputnya diperuntukkan agar dapat menjawab tujuan penelitian, hal ini dilakukan secara terstruktur melalui tahapan yang terjadi dan mengikuti proses tersebut (Sani, Wiliani, \& Husain, 2019). Model itu sendiri merupakan sesuatu dengan parameter spesifik yang dimaksudkan untuk menggambarkan realitas dan hubungan antar variabel yang saling mempengaruhi (Supranto \& Limakrisna, 2019, p. 31). Model dalam penelitian ini dirumuskan sebagai berikut:

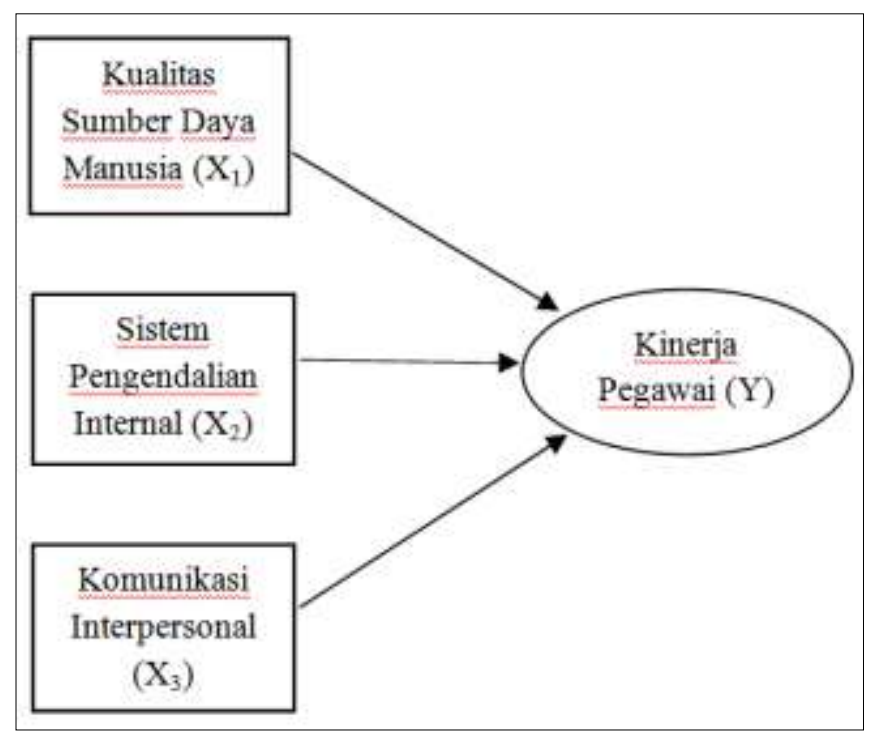

Gambar 1 Model Penelitian

\section{Data, Instrumen, dan Teknik Pengumpulan Data}

Penelitian ini menggunakan data primer dengan instrumen berupa kuesioner atau angket dengan teknik pengumpulan yang memberikan pernyataan secara tertulis yang akan dipilih alternatif jawaban oleh responden, agar penelitian memperoleh data lapangan untuk 
memecahkan masalah penelitian dan menguji hipotesis yang telah ditetapkan (Arikunto, 2016, p. 127). Skala yang digunakan dalam penelitian ini adalah skala Likert dengan perolehan skor $1-5$.

\section{Teknik Analisis Data}

Teknik analisis data menggunakan statistik inferensial yaitu metode statistik yang memungkinkan individu untuk melaksanakan uji pengaruh beberapa variabel terhadap variabel lainnya dalam saat yang bersamaan (Santosa, 2019, p. 3). Persamaan regresi diajukan pada penelitian ini yaitu:

$Y=a+b X_{1}+b X_{2}+b X_{3}+e$

\section{HASIL PENELITIAN DAN PEMBAHASAN}

\section{Deskripsi Responden}

Obyek dalam penelitian adalah pegawai PNS di Kabupaten Karanganyar. Untuk memperoleh mengenai gambaran umum obyek penelitian, peneliti menggunakan kuesioner yang berisi deskripsi dari responden yakni mengenai jenis kelamin. Berikut ini adalah data yang peneliti peroleh mengenai profil responden tersebut:

Tabel 1 Deskripsi Responden berdasarkan Jenis Kelamin

\begin{tabular}{llll}
\hline No. & Jenis Kelamin & Jumlah & Persentase \\
\hline 1. & Perempuan & 45 & 45 \\
2. & Laki-Laki & 55 & 55 \\
& Jumlah & 100 & 100 \\
\hline
\end{tabular}

Sumber: Data Primer yang Diolah, 2020

Dari tabel di atas, responden yang memiliki jenis kelamin perempuan sebanyak 45 (45\%), dan laki-laki sebanyak 55 (55\%). Berdasarkan analisis tersebut dapat diketahui bahwa pegawai PNS di Kabupaten Karanganyar terbesar yang berjenis kelamin pria.

\section{Hasil Pengujian Data}

Hasil pengujian tergantung pada metode analisis data yang digunakan dalam pengujian data, pengujian asumsi regresi pengujian hipotesis beserta batasan-batasannya untuk dasar pengambilan keputusan menerima hipotesis atau tidak menerima hipotesis penelitian. Uji data 
pada penelitian ini diawali melalui uji validitas dari masing-masing item pernyataan dari variabel penelitian.

Tabel 2 Hasil Uji Validitas Instrumen Kualitas Sumber Daya Manusia $\left(\mathrm{X}_{1}\right)$

\begin{tabular}{llll}
\hline $\begin{array}{c}\text { Item } \\
\text { Pertanyaan }\end{array}$ & ritem (skor) & rtabel & Keterangan \\
\hline $\mathrm{X} 1 \_1$ & 0,634 & 0,196 & Valid \\
$\mathrm{X} 1 \_2$ & 0,675 & 0,196 & Valid \\
$\mathrm{X} 1 \_3$ & 0,510 & 0,196 & Valid \\
\hline
\end{tabular}

Sumber: Data Primer yang Diolah, 2020

Berdasarkan tabel 2 dapat disimpulkan bahwa 3 (tiga) item pernyataan masing-masing mempunyai $r_{\text {item }}$ yang lebih besar dari $r_{\text {tabel }}(0,196)$ yaitu $0,634,0,675$ dan 0,510 (X1_1 hingga X1_3). Hal ini menunjukkan bahwa instrumen yang digunakan untuk menyusun konstruk Kualitas Sumber Daya Manusia adalah valid.

Tabel 3 Hasil Uji Validitas Instrumen Sistem Pengendalian Internal $\left(\mathrm{X}_{2}\right)$

\begin{tabular}{llll}
\hline $\begin{array}{c}\text { Item } \\
\text { Pertanyaan }\end{array}$ & r-item (skor) & r-tabel & Keterangan \\
\hline X2_1 & 0,455 & 0,196 & Valid \\
X2_2 & 0,494 & 0,196 & Valid \\
X2_3 & 0,448 & 0,196 & Valid \\
X2_4 & 0,427 & 0,196 & Valid \\
X2_5 & 0,481 & 0,196 & Valid \\
X2_6 & 0,454 & 0,196 & Valid \\
\hline
\end{tabular}

Sumber:

Data Primer yang Diolah, 2020

Berdasarkan tabel 3 dapat disimpulkan bahwa 6 (enam) item pernyataan masing-masing mempunyai $r_{\text {item }}$ yang lebih besar dari $r_{\text {tabel }}(0,196)$ yang berkisar antara 0,400 hingga 0,500 (X2_1 hingga X2_6). Hal ini menunjukkan bahwa instrumen yang digunakan untuk menyusun konstruk Sistem Pengendalian Internal adalah valid.

Tabel 4 Hasil Uji Validitas Instrumen Komunikasi Interpersonal $\left(\mathrm{X}_{3}\right)$

\begin{tabular}{cccc}
\hline Item & r-item (skor) & r-tabel Keterangan \\
Pertanyaan & & \\
\hline
\end{tabular}




\begin{tabular}{llll}
\hline X3_1 & 0,450 & 0,196 & Valid \\
X3_2 & 0,477 & 0,196 & Valid \\
X3_3 & 0,439 & 0,196 & Valid \\
X3_4 & 0,438 & 0,196 & Valid \\
X3_5 & 0,560 & 0,196 & Valid \\
\hline
\end{tabular}

Sumber:

Data Primer yang Diolah, 2020

Berdasarkan tabel 4 dapat disimpulkan bahwa 5 (lima) item pernyataan masing-masing mempunyai $r_{\text {item }}$ yang lebih besar dari $r_{\text {tabel }}(0,196)$ yaitu masing-masing $0,450,0,477,0,439$, 0,438 dan 0,560 (X3_1 hingga X3_5). Hal ini menunjukkan bahwa instrumen yang digunakan untuk menyusun konstruk Komunikasi Interpersonal adalah valid.

Tabel 5 Hasil Uji Validitas Instrumen Kinerja Pegawai (Y)

\begin{tabular}{llll}
\hline $\begin{array}{c}\text { Item } \\
\text { Pertanyaan }\end{array}$ & r-item (skor) & r-tabel & Keterangan \\
\hline Y_1 & 0,565 & 0,196 & Valid \\
Y_2 & 0,436 & 0,196 & Valid \\
Y_3 & 0,323 & 0,196 & Valid \\
Y_4 & 0,532 & 0,196 & Valid \\
Y_5 & 0,404 & 0,196 & Valid \\
\hline
\end{tabular}

Sumber: Data Primer yang Diolah, 2020

Berdasarkan tabel 5 dapat disimpulkan bahwa 5 (lima) item pernyataan masing-masing mempunyai $r_{\text {item }}$ yang lebih besar dari $r_{\text {tabel }}(0,196)$. Hal ini menunjukkan bahwa instrumen yang digunakan untuk menyusun konstruk Kinerja Pegawai adalah valid.

Tabel 6 Hasil Uji Reliabilitas Instrumen Penelitian

\begin{tabular}{llll}
\hline \multicolumn{1}{c}{ Instrumen } & $\begin{array}{l}\text { Cronbach's } \\
\text { Alpha } \text { (skor) }\end{array}$ & r-kritis & Keterangan \\
\hline Kualitas Sumber Daya Manusia & 0,772 & 0,60 & Reliabel \\
Sistem Pengendalian Internal & 0,725 & 0,60 & Reliabel \\
Komunikasi Interpersonal & 0,712 & 0,60 & Reliabel \\
Kinerja Pegawai & 0,690 & 0,60 & Reliabel
\end{tabular}

Sumber: Data Primer yang Diolah, 2020 
Berdasarkan tabel 6 dapat disimpulkan bahwa keseluruhan konstruk yang diteliti mempunyai nilai Cronbach's Alpha yang lebih besar dari $\mathrm{r}_{\text {kritis }}(0,60)$. Hal ini menunjukkan bahwa masingmasing instrumen yang diusulkan dalam penelitian memiliki reliabilitas yang baik.

\section{Hasil Uji Regresi Linier Berganda}

Tabel 7 Hasil Regresi Linier Berganda

\begin{tabular}{llll}
\hline \multicolumn{1}{c}{ Variabel } & $\begin{array}{l}\text { Koefisien } \\
\text { Regresi (skor) }\end{array}$ & $\begin{array}{l}\text { Probabilitas } \\
\text { Signifikansi }\end{array}$ & Hasil Uji \\
\hline Constant & 7,394 & 0,001 & \\
Kualitas Sumber Daya Manusia & 0,230 & 0,043 & Signifikan \\
Sistem Pengendalian Internal & 0,187 & 0,020 & Signifikan \\
Komunikasi Interpersonal & 0,284 & 0,002 & Signifikan \\
\hline
\end{tabular}

Sumber: Data Primer yang Diolah, 2020

Berdasarkan tabel 7 di atas, hasil regresi dapat dikonversikan dalam bentuk persamaan regresi: $\mathrm{Y}=7,394+0,230 \mathrm{X}_{1}+0,187 \mathrm{X}_{2}+0,284 \mathrm{X}_{3}$

Hasil persamaan regresi dinyatakan sebagai berikut:

$\mathrm{a}=7,394$, konstanta sebesar 7,394 artinya apabila variabel Kualitas Sumber Daya Manusia,

Sistem Pengendalian Internal dan Komunikasi Interpersonal tetap atau konstan maka kinerja positif.

$\mathrm{b}_{1}=0,230$, Koefisien regresi Kualitas Sumber Daya Manusia sebesar 0,230 berpengaruh positif terhadap kinerja pegawai artinya apabila Kualitas Sumber Daya Manusia ditingkatkan maka kinerja pegawai meningkat dengan asumsi sistem pengendalian internal dan komunikasi interpersonal tetap atau konstan.

$\mathrm{b}_{2}=0,187$, Koefisien regresi Sistem Pengendalian Internal sebesar 0,187 berpengaruh positif terhadap kinerja pegawai artinya apabila sistem pengendalian internal ditingkatkan maka kinerja pegawai meningkat dengan asumsi kualitas sumber daya manusia dan komunikasi interpersonal tetap atau konstan.

$\mathrm{b}_{3}=0,284$, Koefisien regresi Komunikasi Interpersonal sebesar 0,284 berpengaruh positif terhadap kinerja pegawai artinya apabila komunikasi interpersonal ditingkatkan maka kinerja pegawai meningkat dengan asumsi kualitas sumber daya manusia dan sistem pengendalian internal tetap atau konstan. 
Tabel 7 di atas juga memberikan informasi atas uji signifikansi secara parsial yang dinyatakan sebagai berikut:

a. Nilai t hitung kualitas sumber daya manusia sebesar 2,049 dengan nilai signifikansi sebesar 0,043 lebih kecil dari $\alpha(0,05)$ yang berarti kualitas sumber daya manusia berpengaruh signifikan terhadap kinerja pegawai.

b. Nilai t hitung sistem pengendalian internal sebesar 2,366 dengan nilai signifikansi sebesar 0,020 lebih kecil dari $\alpha(0,05)$ yang berarti sistem pengendalian internal berpengaruh signifikan terhadap kinerja pegawai.

c. Nilai t hitung komunikasi interpersonal sebesar 3,148 dengan nilai signifikansi sebesar 0,002 lebih kecil dari $\alpha(0,05)$ yang berarti komunikasi interpersonal berpengaruh signifikan terhadap kinerja pegawai.

Tabel 8 Hasil Uji Simultan (Uji-F)

\begin{tabular}{lll}
\hline & Skor & \\
\cline { 1 - 2 } $\mathrm{dF}(1 ; 2)$ & $3 ; 96$ & \\
F-statistik & 15,299 & Sumber: Data Primer yang \\
Prob. Sig & 0,000 &
\end{tabular}

Diolah, 2020

Berdasarkan tabel 8 di atas, nilai signifikansi pengaruh kualitas sumber daya manusia, sistem pengendalian internal, dan komunikasi interpersonal terhadap kinerja pegawai sebesar 0,000 lebih kecil dari $\alpha(0,05)$ artinya kualitas SDM, sistem pengendalian internal, dan komunikasi interpersonal berpengaruh signifikan terhadap kinerja pegawai secara simultan.

Tabel 9 Hasil Uji Koefisien Determinasi (R-Square)

\begin{tabular}{ll}
\hline & Skor \\
\hline $\mathrm{R}$ & 0,569 \\
Adj. R-square & 0,302 \\
\hline
\end{tabular}

Sumber: Data Primer yang Diolah, 2020

Berdasarkan tabel 9 di atas, nilai $\mathrm{R}$ diperoleh sebesar 0,569 artinya keterkaitan antara kualitas sumber daya manusia, sistem pengendalian internal, dan komunikasi interpersonal dengan kinerja pegawai cuku erat yaitu 56,9 persen. Skor Adjusted $R$ Square sebesar 0,302 atau 30,2 persen yang berarti variasi variabel kinerja pegawai dijelaskan oleh variabel kualitas sumber 
daya manusia, sistem pengendalian internal, dan komunikasi interpersonal. Sedangkan sisanya 69,8 persen dijelaskan oleh variabel diluar penelitian.

\section{Pembahasan}

Hasil perhitungan uji-t atas variabel kualitas sumber daya manusia menghasilkan probabilitas signifikansi sebesar 0,043 (kurang dari 0,05), maka $\mathrm{H}_{1}$ terbukti. Variabel kualitas sumber daya manusia berpengaruh signifikan terhadap kinerja pegawai PNS di Kabupaten Karanganyar. Berdasarkan dari penelitian tersebut serupa dengan penelitian (Rahayu, Sulindawati, \& Sinarwati, 2014; Aziz, Pratiwi, \& Suyono, 2018) dari penelitian ini kualitas sumber daya manusia berpengaruh signifikan terhadap kinerja pegawai. Langkah-langkah yang direkomendasikan untuk meningkatkan variabel kualitas sumber daya manusia yaitu instansi atau organisasi memerlukan pegawai yang keterampilan dan memiliki pengetahuan teknologi yang sesuai dengan tuntutan bidang pekerjaan, instansi atau organisasi dalam melaksanakan pekerjaan memerlukan pegawai yang memiliki stamina, kekuatan, keterampilan serta karakter yang baik dan instansi atau organisasi memerlukan pegawai yang dalam melaksanakan pekerjaan dengan jujur dan bertanggung jawab agar dapat dinilai baik.

Hasil perhitungan uji-t atas variabel sistem pengendalian internal menghasilkan probabilitas signifikansi sebesar 0,020 (kurang dari 0,05), maka $\mathrm{H}_{2}$ terbukti. Variabel sistem pengendalian internal juga berpengaruh signifikan terhadap kinerja pegawai PNS di Kabupaten Karanganyar. Berdasarkan dari penelitian tersebut serupa dengan penelitian (Zahro, 2016; Aziz, Pratiwi, \& Suyono, 2018) dari penelitian ini sistem pengendalian internal berpengaruh signifikan terhadap kinerja pegawai. Langkah-langkah yang direkomendasikan untuk meningkatkan variabel sistem pengendalian internal yaitu instansi atau organisasi membutuhkan pemimpin yang dapat menegakkan integritas dan nilai etika, membentuk struktur organisasi yang sesuai, dan juga dapat menyusun dan menerapkan kebijakan mengenai pembinaan sumber daya manusia, instansi atau organisasi membutuhkan pemimpin yang dalam pengambilan keputusan dapat bertanggung jawab dan kemudian keputusan tersebut dapat disampaikan kepada bawahan secara tepat waktu, dan instansi atau organisasi membutuhkan pemimpin yang memahami tanggung jawab dan dapat mengendalikan masing-masing bagiannya.

Hasil perhitungan uji-t atas variabel komunikasi interpersonal menghasilkan probabilitas signifikansi sebesar 0,002 (kurang dari 0,05), maka $\mathrm{H}_{3}$ terbukti. Variabel komunikasi interpersonal juga berpengaruh signifikan terhadap kinerja pegawai PNS di Kabupaten Karanganyar. Berdasarkan dari penelitian tersebut serupa dengan penelitian (Pangendaheng, 
2018) dari penelitian ini komunikasi interpersonal berpengaruh signifikan terhadap kinerja pegawai. Langkah-langkah yang direkomendasikan untuk meningkatkan variabel komunikasi interpersonal yaitu instansi atau organisasi mendorong pegawai harus dapat menerima anggota komunikasi lain secara sama rata, instansi atau organisai mendorong pegawai dalam berusaha memahami perasaan orang lain dan juga dapat menempatkan diri di dalam keadaan orang tersebut, dan instansi atau organisasi mendorong pegawai agar dapat menerima pendapat orang lain dengan bersikap jujur, rendah hati dan adil.

\section{KESIMPULAN DAN IMPLIKASI}

Variabel Kualitas Sumber Daya Manusia, Sistem Pengendalian Internal, dan Komunikasi Interpersonal secara simultan dan individu berpengaruh positif dan signifikan terhadap Kinerja Pegawai PNS di Kabupaten Karanganyar. Hasil uji pengaruh menghasilkan adjusted $\mathrm{R}^{2}$ sebesar 0,302 artinya kontribusi variabel Kualitas Sumber Daya Manusia, Sistem Pengendalian Internal, dan Komunikasi Ineterpersonal sebesar 30,2 persen dalam menjelaskan variabel kinerja pegawai, sedangkan sisanya 69,8 persen dipengaruhi oleh faktor lain diluar penelitian seperti budaya organisasi, kepemimpinan, dan komitmen.

Peneliti yang akan datang diharapkan dapat menguji kembali temuan penelitian ini atau mengembangkan kerangka model penelitian ini, pada jenis variabel yang sama maupun berbeda, sehingga dapat memperkuat pengetahuan dengan teori yang diuji dengan mengembangkan konsep atau pendekatan lainnya.

\section{DAFTAR PUSTAKA}

Arikunto, S. (2016). Prosedur Penelitian Suatu Pendekatan Praktik. Jakarta: Rineka Cipta.

Aziz, N. J., Pratiwi, U., \& Suyono, E. (2018). Pengaruh Sistem Pengendalian Intern Pemerintah, Sistem Informasi Manajemen Daerah Dan Kualitas Sumber Daya Manusia Terhadap Kinerja Manajerial Aparatur Pemerintah Daerah. Jurnal Ekonomi, Bisnis dan Akuntansi, 20(4), 1-12. https://doi.org/10.32424/jeba.v20i4.1179

BPS Kabupaten Karanganyar. (2020). 2020 Kabupaten Karanganyar dalam Angka: Karanganyar Regency in Figures. BPS Statistics of Karanganyar Regency.

Hady, H., Henderi, \& Putri, D. M. (2018). The Application of Science Concepts in Management Research Reports Based on Scientific Truth. ATM (Aptisi Transactions on Management), 2(1), 37-44. https://doi.org/10.33050/atm.v2i1.791

Hamid, A. (2011). Otonomi Daerah dan Kualias Pelayanan Publik. Jurnal Academica, 03(01), 535-546. 
Endang Brotojoyo, Veronica Titi Purwantini

Vol. 5 No 2

ISSN : 2541-6995

E ISSN : 2580-5517

Hasibuan, M. S. (2017). Manajemen Sumber Daya Manusia (Cetakan ke-18) (Revisi ed.). Jakarta: PT Bumi Aksara.

Husain, T. (2017). Analisis Determinan Faktor-Faktor Yang Mempengaruhi Niat Penggunaan Software Audit. Jurnal Ilmiah Matrik, 19(2), 131-150. https://doi.org/10.33557/jurnalmatrik.v19i2.381

Husain, T., \& Sani, A. (2020). Kepuasan Pelanggan Toko Online Yang Dipengaruhi Kualitas Produk Dan Layanan. JITK (Jurnal Ilmu Pengetahuan dan Teknologi Komputer), 5(2), 291-296. https://doi.org/10.33480/jitk.v5i2.614

Londong, C. A., Saerang, D. P., \& Koleangan, R. (2015). Faktor-Faktor Yang Mempengaruhi Kinerja Pegawai Negeri Sipil Kota Manado. Jurnal Pembangunan Ekonomi dan Keuangan Daerah, 17(2). https://doi.org/10.35794/jpekd.10251.17.2.2015

Moeheriono. (2014). Pengukuran Kinerja Berbasis Kompetensi, Edisi Revisi. Jakarta: RajaGrafindo Persada.

Pangendaheng, S. A. (2018). Pengaruh Komunikasi Internal Organisasi dan Komitmen Organisational terhadap Kinerja Karyawan Bank Mayapada Cabang Ruko Mapan Indah. AGORa, 6(1).

PP RI. (2008). Peraturan Pemerintah Republik Indonesia Nomor 60 Tahun 2008 tentang Sistem Pengendalian Intern Pemerintah. Peraturan Pemerintah, Jakarta.

Rahayu, N. L., Sulindawati, N. L., \& Sinarwati, N. K. (2014). Pengaruh Partisipasi Penyusunan Anggaran, Kualitas Sumber Daya Manusia dan Penerapan System Informasi Akuntansi terhadap Kinerja di Pemerintah Daerah. Jurnal Ilmiah Mahasiswa Akuntansi UNDIKSHA, 2(1). http://dx.doi.org/10.23887/jimat.v2i1.3401

Rismayadi, B., \& Maemunah, M. (2018). Improving Performance of Karawang Civil Servant (ASN) West Java Province. International Review of Management and Marketing, 8(2), 90-95.

Rivai, V. (2015). Manajemen Sumber Daya Manusia Untuk Perusahaan: Dari Teori ke Praktik (Edisi ke-3). Jakarta: PT. Raja Grafindo Persada.

Roem. (2019). Komunikasi Interpersonal (Cetakan ke-1). Malang: CV IRDH.

Sani, A., Wiliani, N., \& Husain, T. (2019). Spreadsheet Usability Testing in Nielsen's Model among Users of ITSMEs to Improve Company Performance. European Journal of Scientific Exploration, 2(6), 1-9.

Santosa, A. D. (2019). Analisis Multivariat (Cetakan Ketiga). Yogyakarta: Penerbit Kepel Press.

Sungkono, \& Tuhagana, A. (2020). Pengaruh Kepemimpinan dan Lingkungan Kerja terhadap Kinerja Karyawan pada Perusahaan Kawasan Industri di Kabupaten Karawang. Jurnal Buana Ilmu, 4(2), 124-137. https://doi.org/10.36805/bi.v4i2.1132

Supranto, J., \& Limakrisna, N. (2019). Petunjuk Praktis Penelitian Ilmiah untuk Menyusun Skripsi, Tesis dan Disertasi (Edisi Kelima). Bogor: Penerbit Mitra Wacana Media. 
Sutjiatmi, S. (2010). Reformasi Birokrasi di Era Otonomi Daerah. CERMIN (047).

Wiranata, A. D., Irwansyah, Budiyantara, A., \& Sani, A. (2020). Pemilihan Karyawan Teladan Menggunakan Metode SAW dan TOPSIS. Journal of Business and Audit Information Systems, 3(1), 22-35. http://dx.doi.org/10.30813/jbase.v3i1.2060

Zahro, N. I. (2016). Pengaruh Sistem Informasi Akuntansi dan Pengendalian Internal terhadap Kinerja Pemerintah di Daerah Kabupaten Kudus. Prosiding Seminar Nasional Multi Disiplin Ilmu dan Call for Papers. SENDI_U) Ke-2. Semarang: Universitas Stikubank. 